\title{
CRISE AMBIENTAL, POLÍTICA CLIMÁTICA \\ E O TURISMO: ALGUMAS REFLEXÕES
}

\section{ENVIRONMENTAL CRISIS, CLIMATE POLICY AND TOURISM: SOME REFLECTIONS}

\section{Isabel Jurema Grimm}

Pós-Doutoranda em Gestão Urbana da Pontifícia Universidade Católica do Paraná (PUCPR), Gestão Ambiental pela Universidade Positivo (UP). Turismóloga.

Doutora em Meio Ambiente e Desenvolvimento pela Universidade Federal do Paraná (UFPR).

\section{Carlos Alberto Cioce Sampaio}

Professor da Fundação Universidade Regional de Blumenau e Universidade Positivo (UP). PósDoutor em Ecossocioeconomia, Cooperativismo Corporativo e Ciências Ambientais. Administrador. Doutor em Planejamento e Gestão Organizacional.

\section{Endereço para correspondência:} Isabel Jurema Grimm - Rua Vinícius de Morais, 109- Pilarzinho 82115-060 - Curitiba (PR), Brasil E-mail: isabelgrimm@gmail.com

Recebido: 22/06/2016

Aceito: 25/05/2017

\section{RESUMO}

Neste artigo, busca-se analisar possíveis impactos e consequências das mudanças climáticas no sistema turístico, em cenários prospectivos no Brasil e no mundo. Metodologicamente, constitui-se de pesquisa bibliográfica e documental com abordagem interdisciplinar e enfoque exploratório. Delimita-se o referencial teórico-metodológico, voltando-se a evidências e perspectivas que envolvem mudanças climáticas e o turismo internacional. A coleta de dados ocorreu com entrevistas estruturadas junto aos especialistas de diferentes áreas do conhecimento: meteorologia, física, sociologia, ciências econômicas, geografia, turismo, administração, ciências sociais, biologia e engenharia ambiental. Todos demonstram aproximação com pelo menos uma das categorias: mudanças climáticas, turismo, impactos ambientais. Como resultado, tem-se evidências de impactos ambientais sobre a atividade turística internacional, o que pode indicar a necessidade de inclusão do turismo na política climática global orientando o setor para medidas de adaptação e mitigação às mudanças climáticas, tanto quanto para os desafios e oportunidades da política de baixo carbono no desenvolvimento do turismo sustentável.

Palavras-chave: mudanças climáticas; turismo; adaptação; mitigação; baixo carbono.

\section{ABSTRACT}

This paper aims to analyze several possible impacts and consequences about climate change on the tourism system, in prospective scenarios in Brazil and in the world. Its methodology consists in bibliographical and documentary research with an interdisciplinary approaching about an exploratory focusing. Regarding the theoretical-methodological reference, it intends to create some embryonic notions about evidences and perspectives which are involving global climatic changes and also the international tourism. Data's gathering was carried out through structured interviews with specialists from different areas of knowledge, as such as: meteorology, physics, sociology, economics, geography, tourism, administration, social sciences, biology, and environmental engineering. All show an approximation with at least one of the categories: climate change, tourism, environmental impacts. As a result, there is evidence of environmental impacts on international tourism activity, which may indicate the need to include tourism in global climate policy, guiding the sector toward measures to adapt and mitigate climate changes, as well as to the challenges and opportunities for the development of sustainable tourism.

Keywords: climate change; tourism; adaptation; mitigation; low carbon. 


\section{INTRODUÇÃO}

A atividade turística sempre teve que afrontar diversas circunstâncias e se adaptar a novas condições, sejam econômicas, legais ou sociais. Entretanto, em face de uma nova situação, como a mudança climática, o setor se encontra diante de um fenômeno que não pode ser controlado e que exige que sejam planificadas estratégias de adaptação e mitigação que permitam desenvolver atividades turísticas em longo prazo, com vistas ao enfrentamento da nova ordem climática global. Devido à gravidade das mudanças climáticas projetadas e seus impactos, o tema está sendo integrado a pesquisas e iniciativas sustentáveis de desenvolvimento do turismo (HALL et al., 2015; GRIMM, 2016).

O turismo, a exemplo de outros setores econômicos, é dependente da energia, em especial da energia derivada de combustíveis fósseis. Globalmente, o setor é responsável por cerca de $5 \%$ das emissões de $\mathrm{CO}_{2}$, provenientes da ação antrópica. Destes, o transporte de turistas por avião contribui com $40 \%$ das emissões, por automóvel $32 \%$ e outros meios de transporte contribuem com $3 \%$ das emissões. O setor de alojamento e as atividades de recreação e lazer, representam 25\% das emissões de gases de efeito estufa do setor (OMT, 2008; SIMPSON et al., 2008; MORENO, 2010; RIBOT, 2011; GRIMM et al., 2013; GRIMM, 2016). Entretanto, esses cálculos não contabilizam os efeitos adicionais da aviação em alta altitude, sobre os quais ainda há incerteza científica. De acordo com a Organização Mundial do Turismo (OMT, 2008), a contribuição do turismo para a mudança climática global (incluindo efeitos de forçamento radiativo) é estimada em $14 \%$.

Previsões sinalizam que a mudança climática vai reduzir a taxa de crescimento dos movimentos turísticos internacionais, incidindo especialmente em destinos de longa e média distância. Nesse cenário, haverá, mundialmente, regiões "ganhadoras" e "perdedoras".
Esse posicionamento responderá a uma combinação de vários fatores: maturidade dos mercados emissores, novas condições climáticas relativas de determinada região e a capacidade de adaptação da mesma frente a essas mudanças (OMT, 2008; GÖSSLING et al., 2009; MACHETE, 2011).

Diante disso, o turismo tem papel relevante nesse debate, uma vez que é afetado pelos efeitos das mudanças climáticas, ao mesmo tempo que contribui para o aquecimento global (SIMPSON et al., 2008; MORENO, 2010; MATZARAKIS, 2008). Portanto, sua inclusão no campo da política climática - a exemplo de outros setores econômicos mundiais como a agricultura, energia, pecuária, pesca etc. - é necessária para garantir o desenvolvimento de estratégias de enfrentamento aos desafios impostos pelas mudanças climáticas.

Nesse contexto, este artigo busca analisar possíveis impactos e consequências das mudanças climáticas no sistema turístico - em cenários prospectivos no Brasil e no turismo internacional - e a inserção do setor na política global de redução de emissões. A metodologia tem viés interdisciplinar e sistêmico, com base em dados bibliográficos e documentais. Especialistas de diferentes áreas disciplinares colaboraram para a coleta de dados, que por meio de entrevistas estruturadas, aportaram para este constructo. Todos demonstraram aproximação com pelo menos uma das categorias: mudanças climáticas; turismo; e impactos ambientais. Como resultado, têm-se evidências de impactos ambientais sobre o turismo internacional, o que pode indicar a necessidade de inclusão do turismo na política climática global, orientando o setor para medidas de adaptação e mitigação às mudanças climáticas, tanto quanto para os desafios e oportunidades da política de baixo carbono no desenvolvimento do turismo sustentável.

\section{REFERENCIAL TEÓRICO}

\section{A crise ambiental contemporânea e o turismo}

O modelo de civilização estabelecido a partir da Revolução Industrial, com sua forma de produção e organização do trabalho, a mecanização da agricultura, o uso intenso de agrotóxicos, o aumento populacional e sua concentração nas cidades, intensificou a explora- ção dos recursos naturais associada a um processo de formação de mercado mundial, que transforma desde a matéria-prima até os mais sofisticados produtos em demandas mundiais. Esse processo "levou à degradação ambiental de forma diferenciada entre as nações, 
quer seja pela exaustão dos recursos naturais explorados, quer seja pelo destino inadequado dos resíduos gerados pelas atividades econômicas" (MARTINS COSTA, 2011, p. 4).

Contudo, Foladori (2001) destaca que, apesar das relações capitalistas pressionarem mais fortemente a destruição do meio ambiente, isso não quer dizer que não haja pressões em formas diferentes de economia de produção que causem o mesmo efeito. Para Leff (2010), outras atividades humanas também têm provocado efeitos negativos sobre a natureza e o turismo, o que vem sendo discutido, ora como atividade econômica, ora como atividade socioeconômica-ambiental.

Embora o turismo seja considerado menos agressivo que outros setores econômicos, suas dimensões podem trazer consequências negativas ao meio ambiente em termos físicos e sociais, contribuindo, mesmo que em menor escala, para a crise ambiental contemporânea. O Quadro 1 apresenta alguns impactos socioam- bientais do turismo mundialmente relacionados à crise ambiental atual (GRIMM, 2016).

O turismo e a mudança climática possuem estreita relação, podendo ser observadas alterações do clima que já afetam ou afetarão o turismo em nível global, de forma direta ou indireta. Os impactos diretos se referem, por exemplo, à alteração nas estações climáticas (com diminuição da cobertura da neve nos destinos de inverno alpino), que influencia a escolha do destino e, consequentemente, o fluxo turístico, além de acarretar em danos à infraestrutura, aumento dos custos operacionais. (SCOTT et al., 2012). Os efeitos indiretos incluem os impactos das mudanças climáticas sobre o ambiente natural e a diminuição da biodiversidade, que por sua vez irá reduzir a atração ambiental da localidade (FITCHETT et al., 2016). Scott et al. (2012) incluem como impactos indiretos as alterações ambientais induzidas pelo clima que afetam o meio ambiente natural dos destinos (como a erosão costeira derivada do aumento do nível do mar ou a redução da biodiversidade

Quadro 1 - Impactos socioambientais do turismo internacional e sua relação com a crise ambiental contemporânea.

\begin{tabular}{|c|c|c|}
\hline Fenômeno & Relação com o turismo & $\begin{array}{l}\text { Relação com a crise } \\
\text { ambiental contemporânea }\end{array}$ \\
\hline $\begin{array}{l}\text { Produção e } \\
\text { consumo de } \\
\text { energia }\end{array}$ & $\begin{array}{l}\text { Transporte } \\
\text { Refrigeração }\end{array}$ & $\begin{array}{l}\text { Emissões de gases de efeito estufa. } \\
\text { Destruição da camada de ozônio. } \\
\text { Poluição do ar. }\end{array}$ \\
\hline $\begin{array}{l}\text { Consumo de } \\
\text { água }\end{array}$ & $\begin{array}{l}\text { Aumento do consumo durante a temporada } \\
\text { turística. } \\
\text { Uso desordenado e ilegal do recurso. }\end{array}$ & Escassez do recurso. \\
\hline $\begin{array}{l}\text { Uso e ocupação } \\
\text { do solo }\end{array}$ & $\begin{array}{l}\text { Remoção de vegetação para construção } \\
\text { de hotéis, áreas de lazer, rodovias e outras } \\
\text { infraestruturas. } \\
\text { Especulação imobiliária. }\end{array}$ & $\begin{array}{l}\text { Erosão do solo. } \\
\text { Perda de biodiversidade. } \\
\text { Destruição de habitat e da paisagem. } \\
\text { Alteração de dunas costeiras. } \\
\text { Crescimento desordenado. }\end{array}$ \\
\hline Contaminantes & $\begin{array}{l}\text { Uso de óleos, lubrificantes, hidrocarbonetos, } \\
\text { detergentes, emissão de esgoto. }\end{array}$ & Contaminação do solo, água e ar. \\
\hline Migrações & Temporada turística & $\begin{array}{l}\text { Alta taxa de produção e mau descarte do lixo. } \\
\text { Padrões de consumo. } \\
\text { Mudança comportamental e cultural. }\end{array}$ \\
\hline
\end{tabular}


decorrente de um clima em mudança), influenciando novamente nos custos, riscos e escolhas. Há, ainda, desde mudanças socioeconômicas indiretas induzidas pelo clima, ocasionando danos ao desenvolvimento e ao crescimento do turismo, até instabilidade e mudança de atitudes em relação à escolha do destino em viagens. Em resposta a esses impactos, podem surgir políticas, como as de mitigação, em outros setores econômicos, afetando o turismo e o transporte turístico de várias maneiras (SCOTT et al., 2012).

Como resposta a essa situação, surgem alternativas ecologicamente menos impactantes da atividade como o turismo de base comunitária ${ }^{1}$, o ecoturismo, o turismo rural entre outras, que podem contribuir para "emissões líquidas zero" (GRIMM et al., 2013), ou seja, que atuem para um equilíbrio entre a quantidade de $\mathrm{CO}_{2}$ liberado na atmosfera em decorrência da atividade e a quantidade dela retirada. Contudo, é importante observar que, apesar de poder promover um estilo de vida ativa e saudável, o turismo baseia-se no elevado custo do consumo de recursos com crescente demanda dos consumidores, colaborando para a emissão de gases de efeito estufa (GEE).

Fayos-Solà (2010) ressalta que é fundamental diferenciar as etapas da atividade turística para assim relacionar a responsabilidade dos turistas nas emissões de GEE. $\mathrm{O}$ autor relaciona quatro fases. A fase prévia, que considera as preferências e motivações que condicionam a escolha do destino; nessa fase os impactos ambientais são relativamente baixos. A fase de deslocamento, que suscita preocupações pelo alto grau de consumo de energia. A fase de estadia, cujos impactos e emissões dos turistas não devem ser superiores às atividades de seu lugar de residencial habitual. Finalmente, a fase do pós-viagem, considerada de reflexão e avaliação da experiência, na qual deve-se levar em conta as percepções e comportamentos do turista em relação às questões da mudança do clima (FAYOS-SOLÀ, 2010, p. 297-298).
Frente a esse cenário, o desenvolvimento do turismo internacional passou a ser abordado sob uma perspectiva sustentável, cuja prática, embora de difícil delimitação, é definida pela OMT (2003), "como aquele que satisfaz as necessidades dos turistas, das regiões receptoras ao mesmo tempo que protege e potencializa novas oportunidades para o futuro". Esse conceito encontrou muitas críticas, pois demonstra o viés utilitarista propagado pela OMT que, apesar de histórico, não incorporou outras dimensões importantes como a gestão de todos os recursos existentes, tanto do ponto de vista da satisfação das necessidades econômicas, sociais e estéticas quanto da manutenção da integridade cultural, dos processos ecológicos essenciais, da diversidade biológica e dos sistemas de suporte à vida (CANDIOTTO, 2011). De toda forma, Beni (2006) defende que o turismo sustentável deve pressupor viabilidade econômica e social, privilegiando simultaneamente a cultura local e o ambiente. Nessa esteira, Ruschmann (2008) argumenta que o turismo sustentável deve incorporar a existência de turistas mais responsáveis, privilegiando sua interação com as comunidades receptoras nos campos social, cultural e ambiental de forma equilibrada.

O desenvolvimento do turismo como atividade econômica deve reconhecer a necessidade de planejamento, tendo a complexidade do fenômeno como problemática. Deve-se observar e compreender sua transversalidade e intersetorialidade sistêmica, como forma de promover mudanças que atuem como motivadoras do desenvolvimento. Assim como a globalização democratizou e internacionalizou o mercado turístico, desencadeou também a necessidade de práticas de gestão e planejamento diferenciadas, a partir de paradigmas globais atentos à sustentabilidade local, que contraponham a perversa lógica de privatizar o lucro e socializar as perdas, e potencializem o enfrentamento das adversidades resultantes da mudança climática (GRIMM, 2016).

\section{Desafios das mudanças climáticas para o turismo global}

Como atividade relacionada com o clima, o turismo se vê afetado - positiva ou negativamente - por esse sistema, em dois aspectos fundamentais: a mudança nas condições climáticas (temperatura, pluviometria,

\footnotetext{
${ }^{1}$ Estratégia de sobrevivência e comunicação social de conservação de modos de vida e preservação da biodiversidade, organizado associativamente em territórios, como arranjos socioprodutivos e políticos de base comunitária, que se valem do consumo solidário de bens e serviços (SAMPAIO, 2011, p. 27).
} 
frequência de fenômenos climáticos extremos etc.) e as mudanças que se produzem nos destinos, relacionadas com a frequência da mudança de temperatura. De acordo com Giménez (2007, p. 107), os segmentos turísticos que deverão ser mais afetados com as mudanças do clima são: o turismo de neve (esqui), o turismo de sol e praia, o turismo esportivo (golf), o turismo rural e os esportes náuticos. Os menos afetados são: o turismo de natureza, o turismo de congresso e eventos e o turismo cultural.

Contemporaneamente, o principal desafio do turismo internacional é contribuir para a redução de suas emissões, que deverão aumentar rapidamente nas próxi-

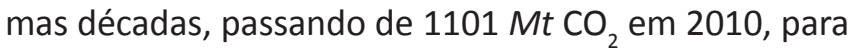
$2957 \mathrm{Mt} \mathrm{CO}$ até 2050 (GÖSSLING \& PEETERS, 2015), resultante do rápido crescimento do volume e distância das viagens aéreas. A exemplo de outros setores econômicos, a participação do turismo nas emissões antropogênicas aumentará consideravelmente. Diante dessas tendências, as emissões do turismo subiriam no patamar global de $\mathrm{CO}_{2}$ em um cenário de $2^{\circ} \mathrm{C}$, isto é, mantendo o aquecimento global abaixo dessa temperatura, até meados deste século (SCOTT et al., 2010).

Reconhecendo a magnitude dos potenciais impactos que a mudança do clima poderá representar para o setor, a OMT (2008) publicou o relatório "A mudança climática e turismo - Responder aos desafios globais", o qual analisa a relação entre as mudanças climáticas e o turismo, identificando os principais impactos em regiões e atividades, e os possíveis meios de adaptação e mitigação do setor.

Em alusão a esses impactos, vale fazer duas considerações: a primeira em relação às implicações que já estão sendo observadas em âmbito global, e ações que devem ser tomadas para amenizar os efeitos deletérios decorrentes do fenômeno climático; a segunda é que ele reflete o outro lado da situação que caracteriza a relação generalizada entre mudança climática e turismo - o reconhecimento de que o turismo, apesar de ser afetado pelas mudanças climáticas, também tem nelas uma poderosa força motriz (MATZARAKIS, 2008; MORENO, 2010).

A mudança climática poderá afetar negativamente o conjunto do sistema turístico (SISTUR) quanto à oferta, à demanda, ao espaço geográfico turístico e aos agentes. Esta poderá também aumentar a pressão para a redução do consumo de energia, exigindo ações de redução e ecoeficiência. As alterações induzidas pelo preço da energia e do transporte poderão ter efeito nas tarifas e nos destinos mais distantes dos núcleos emissores. Tudo isso repercutirá na necessidade de estratégias para o fomento de sistemas menos poluentes, de planos de mobilidade sustentáveis nos destinos, estímulo às viagens de lazer e férias mais próximas da residência, implantação de sistema de energia renovável, sistemas de gestão ambiental e medidas de adaptação do setor turístico às mudanças climáticas (MACHETE, 2011; GRIMM, 2016).

Outros fenômenos naturais relacionados ao tempo e ao clima também poderão afetar o setor de turismo:

1. geológicos: terremotos, tsunamis e erupções vulcânicas;

2. eventos de tempestades: ciclones tropicais, tempestades extratropicais (de inverno), tornados tempestades e tempestades de monções regionais;

3. eventos de chuva: inundações, tempestades, ondas altas, chuva forte, granizo e relâmpago;

4. degelo: blocos de gelo e icebergs à deriva; e

5. o efeito el niño/la niña: alterações climáticas (IPCC, 2014).

Estes riscos são relevantes à segurança das pessoas, aos bens do setor turístico e também aos turistas.

Os impactos poderão comprometer a atratividade e singularidade de paisagens em razão da erosão de praias, branqueamento de corais, degelo de geleiras e até mesmo o desaparecimento de destinos turísticos insulares em todo o mundo. Poderão ainda afetar destinos turísticos diretamente, causando perdas e prejuízos à indústria hoteleira e demais serviços disponíveis em suas cercanias.

Eventos climáticos decorrentes de temperaturas extremas, modificações significativas do ciclo hidrológico ou aumento na velocidade dos ventos, demandarão atenção especial dos destinos turísticos quanto à sua infraestrutura e medidas adicionais em caso de emergências decorrentes de desastres naturais. $O$ transporte poderá sofrer aumento de preço pela inviabilida- 
de de acesso aos destinos, decorrente de quedas de barreiras, alagamentos, entre outros transtornos que afetam estradas, pontes, aeroportos, canais etc. (OMT, 2007). A disponibilidade de água potável, outro fator preponderante para manutenção dos destinos, também poderá ter seu fornecimento afetado.

Entre os aspectos de vulnerabilidade do setor, destacase a construção de infraestrutura turística e de comunicação em áreas de risco, particularmente em encostas e morros mais expostos aos impactos de fenômenos hidrometeorológicos extremos. A sazonalidade alterada, o estresse térmico para os turistas e a transmissão de doenças infecciosas também poderão ser relevantes. Segmentos turísticos de sol e praia, ecoturismo, esportes de neve, entre outros, poderão ser influenciados por este fenômeno quando expostos a eventos climáticos, afetando sua infraestrutura e exigindo medidas de preparação para situações de emergência, elevando os gastos de manutenção e interrompendo, por vezes, a atividade comercial (GRIMM, 2016). De acordo com a OMT (2007), isso significa que, mesmo sob condições atuais, a rentabilidade e a viabilidade dos destinos são pelo menos parcialmente influenciadas pelo clima.

Embora o turismo internacional se apresente sensível aos eventos do clima e suas variações, até recentemente, tanto o setor como a comunidade acadêmica

\section{O turismo e a política climática global}

Em meio a divergentes argumentos científicos sobre o aquecimento global e suas causas antropogênicas, uma vez que a questão não goza de unanimidade na comunidade científica, é possível constatar que a ciência das mudanças climáticas está envolvida em inúmeras incertezas, além de estar sujeita a interesses políticos aparentemente ocultos (MOLION, 2008; LINO, 2009). Tudo parte da ideia de que cientistas congregados ao Painel Intergovernamental para as $\mathrm{Mu}$ danças Climáticas (IPCC) e demais pesquisadores que concordam com o painel possuem razão ao defender a tese de que o aquecimento global existe, nos afeta e possui origem em práticas sociais (emissões antrópicas, desmatamento que diminui a umidade do ar, impermeabilização do solo nas grandes cidades etc.). $\mathrm{O}$ discurso ganhou proporção à medida que tais suspeitas projetaram dados pontuais para uma possível catástrofe global. pouco haviam pesquisado os impactos das alterações climáticas na atividade turística, ou o peso que o turismo e atividades a ele relacionadas têm surtido em mudanças ambientais e globais. Apesar dos progressos observados na última década, algumas lacunas no conhecimento sobre as áreas de impacto e a percepção dos operadores do turismo sobre os riscos das alterações climáticas e a capacidade de adaptação indicam que o setor não está preparado para os desafios que poderão decorrer das mudanças climáticas (SCOTT \& LEMIEUXA, 2009; SCOTT et al., 2012).

Os impactos da mudança climática no setor turístico geram certo grau de incertezas, superior ao de impactos provenientes de outros setores econômicos. Portanto, seja qual for o resultado ambiental da mudança do clima, o turismo não pode ser visto isoladamente, pois qualquer mudança no padrão da demanda pode acarretar impactos amplos em muitos destinos, refletindo também nas áreas da política econômica e social (GRIMM, 2016). Frente a esta realidade, a OMT vem fortalecendo o debate sobre mudanças climáticas globais, o que reflete a preocupação que o tema traz para o setor turístico, para os próprios turistas e para as economias que se apoiam no gasto derivado, tendo em vista que os efeitos da mudança do clima poderão afetar todo o sistema turístico.

Em meio ao debate sobre causas e consequências da mudança climática, o turismo ganhou notoriedade, uma vez que seu desenvolvimento tem tributado para o aquecimento global. Pesquisas têm aumentado o domínio do turismo e sua relação com esse fenômeno, sendo sua presença notada em publicações de revistas científicas, documentos governamentais e eventos internacionais sobre o tema (SCOTT et al., 2012; GRIMM et al., 2013). Todavia, como exposto anteriormente, a produção científica que debata o turismo e sua relação com a mudança climática ainda é frágil e insuficiente.

De toda forma, alguns exemplos podem ser destacados, como a realização da Primeira Conferência Internacional sobre as Mudanças Climáticas e o Turismo, em 2003 na ilha de Djarba, na Tunísia, organizada pela OMT e pelas Nações Unidas. A ocasião buscou a cooperação internacional para concretizar, de um lado, ações comuns e homogêneas para o enfrentamento de 
mudanças climáticas, e por outro, as possibilidades de diminuição de emissões de GEE geradas pelo turismo em âmbito mundial. $O$ encontro não teve o intuito de manter um debate puramente científico, nem de abraçar a totalidade das conhecidas implicações sociais e ambientais que a mudança climática pode ter na sociedade, mas sim fortificar as bases da relação entre turismo e mudanças climáticas, pela importância econômica que a atividade representa em muitos países, principalmente nas pequenas ilhas e em países em vias de desenvolvimento.

A Declaração de Djarba foi produzida durante o evento, conferindo ênfase à importância dos recursos hídricos para o setor de turismo e sua vinculação com as mudanças climáticas. A vulnerabilidade do desenvolvimento do turismo em ecossistemas sensíveis como em regiões costeiras, montanhosas, terras áridas e ilhas foi enfatizada. $O$ documento dedicou-se a apoiar e estimular organizações internacionais para que estudem e investiguem os impactos recíprocos do turismo e das mudanças climáticas, incluindo lugares de interesse cultural e/ou arqueológico, em cooperação com autoridades públicas, instituições acadêmicas, organizações não governamentais (ONGs) e comunidades locais. Destacou-se que organismos internacionais, financeiros e bilaterais das Nações Unidas devem apoiar os governos de países em desenvolvimento, em particular os menos desenvolvidos, para os quais o turismo representa um setor econômico fundamental no combate à pobreza, formulando planos de ação adequados às realidades locais. Na ocasião, foram destacadas medidas de mitigação para uso de tecnologias e logística apropriadas que estimulem o consumo racional de energia, minimizando a contribuição do turismo na emissão de GEE (OMT, 2003)

Em 2007, a OMT, o Programa das Nações Unidas para o Meio Ambiente (PNUMA) e a Organização Meteorológica Mundial (OMM), com o apoio do Foro Econômico Mundial e do governo da Suíça, realizaram em Davos a Segunda Conferência Internacional sobre Mudanças Climáticas e o Turismo, com o objetivo de manter as discussões sobre a temática e ampliar seus estudos.

Na oportunidade, um grupo de especialistas de sete países realizou um diagnóstico sobre os impactos da mudança climática, exigindo dos organismos responsáveis a elaboração de políticas públicas de turismo em termos nacional e internacional. A Declaração de Da- vos, em um documento intitulado "Cambio climático y turismo: responder a los retos mundiales" , oferece um resumo atual do conhecimento sobre os impactos atuais e futuros do fenômeno nos destinos turísticos no mundo, possíveis efeitos na demanda turística, níveis e tendências atuais das emissões de GEE gerado pelo setor e uma sinopse das respostas normativas e de gestão dos principais grupos envolvidos (organizações internacionais, administrações públicas, setor de turismo) interessados na adaptação e mitigação dos efeitos da mudanças climática (OMT, 2008).

Recentemente, em Berlim, na Alemanha, um grupo de 30 especialistas em turismo, provenientes de 19 países, reuniram-se com o objetivo de questionar os caminhos do turismo e a efetividade da sua forma de desenvolvimento para o alcance dos objetivos de desenvolvimento sustentável, e a inclusão do turismo na Agenda 2030. Na ocasião, foi elaborada a Declaração de Berlim: Transformar o Turismo. O documento apresenta, entre outras, preocupações diretas sobre a relação do turismo com as mudanças do clima:

\begin{abstract}
As mudanças climáticas são mais fortemente percebidas pela população mais pobre do mundo. O turismo é, ao mesmo tempo, um vetor e uma vítima das mudanças climáticas. É urgente repensar o atual modelo do turismo que depende cada vez mais das viagens aéreas e de curta duração, o que definitivamente não contribui para o desenvolvimento sustentável.
\end{abstract}

\footnotetext{
Nos preocupa a forma como as soluções tecnológicas são superestimadas em detrimento de mudanças de comportamento e no desenvolvimento de produtos para diminuição significativa das emissões de gases e do efeito estufa (Declaração de Berlim: Transformar o Turismo, 2017, p. 2).
}

Tal iniciativa demonstrou atenção e organização da comunidade científica internacional na mobilização em prol de iniciativas de apoio e estratégias de mitigação e adaptação, que reduzam vulnerabilidades e riscos em destinos turísticos e promovam seu desenvolvimento sustentável. Também evidenciou a importância do turista na escolha consciente e na forma responsável de realizar suas viagens, e a importância do setor para a redução da pobreza, em especial em países em vias de desenvolvimento.

O turismo desempenha papel potencialmente importante e positivo em resposta aos principais desafios da sustentabilidade em nosso tempo. No entanto, o 
setor não poderá fazer frente aos problemas das mudanças ambientais, climáticas e de redução da pobreza de forma isolada. A atividade deve atuar em escala global, para poder contribuir para a consecução dos Objetivos de Desenvolvimento Sustentável (ODS) das Nações Unidas. Para isso, Scott et al. (2016) destacam a necessidade da elaboração de estratégias normativas coerentes, que desvinculem o crescimento turístico previsto para as próximas décadas do aumento do consumo de energia e da emissão de GEE, proveniente principalmente do transporte turístico, em especial da aviação, por meio de intervenções regulatórias mais eficientes.

Contudo, parece haver uma forte relutância dentro do setor do turismo em aceitar um futuro com menos transporte aéreo, que atualmente cobre apenas $17 \%$ das viagens turísticas globais, em prol de viagens por modais de transporte de baixo impacto, como o trem e o ônibus (GÖSSLING et al., 2010). Como o turismo não considera tais futuros, os governos deverão assumir mecanismo de preços justos, sistemas regulatórios ou de comércio de emissões para o setor, a fim de desenvolver novos produtos de menor impacto (PEETERS et al., 2006).

\section{MATERIAIS E MÉTODOS}

O estudo foi realizado a partir de análise bibliográfica e documental. Para o construto teórico, considerouse o tema turismo e sua interação com as mudanças climáticas. Foram analisados 30 artigos disponíveis na base de dados da Coordenação de Aperfeiçoamento de Pessoal de Nível Superior (CAPES) - scielo, sciencedirect, sbecotur - no período de 2008 a 2015. A seleção baseou-se nas palavras "turismo", "mudanças climáticas", "adaptação", "mitigação" e "política climática" constantes em títulos, resumos e/ou palavras-chave e disponíveis nos idiomas português, espanhol e inglês. Ao serem localizados, os artigos passaram a compor os

\section{Instrumental da pesquisa}

O instrumental foi composto por entrevistas estruturadas, levando-se em conta que o colaborador deveria ter aproximação com pelo menos duas das grandes áreas: mudanças climáticas, turismo, desenvolvimento e política climática. A pesquisa, realizada em 2014 e 2015, foi constituída em etapas:

- seleção dos especialistas: participantes de universidades nacionais e estrangeiras - Coimbra, Barcelona, Austral do Chile, King's College London, Universidade Estadual do Ceará, Universidade do Estado da Bahia, Universidade Federal do Pará, Universidade Estadual de São Paulo; colaboradores de instituições como IPCC, o Painel Brasileiro para as Mudanças Climáticas (PBMC) e o Instituto Nacional de Pesquisas Espaciais (Inpe). No total, houve contribuição de 15 especialistas das áreas disciplinares: meteorologia, física, sociologia, ciências econômi- dados de uma planilha Excel. Posteriormente, realizouse a análise dos textos. Os dados documentais foram pesquisados no site da OMT e utilizados somente na composição do referencial teórico.

Nesse ponto, algumas lacunas impediram a fluência da pesquisa, pois bibliografias nesse campo são escassas considerando a inovação do tema, em especial os estudos dos impactos da mudança do clima sobre os turismos internacional e nacional. Diante disso, foram realizadas entrevistas com pesquisadores, oriundos de diferentes áreas do conhecimento, compondo um quadro interdisciplinar de especialistas.

cas, geografia, turismo, administração, ciências sociais, biologia e engenharia ambiental;

- convite via telefone ou e-mail, informando os objetivos da pesquisa;

- envio do questionário via e-mail ou entrevista realizada por telefone; e

- análise das informações para verificar a validade dos dados. Nesse ponto, o retorno dos questionários foi satisfatório, não sendo necessário solicitar esclarecimentos ou novas informações.

Por se tratar de uma pesquisa bastante específica, elaborou-se um questionário que foi enviado a todos os colaboradores, independentemente de sua área de 
formação, com vistas a responder ao objetivo da pesquisa: analisar possíveis impactos e consequências das mudanças climáticas no sistema turístico em cenários prospectivos no Brasil e no turismo internacional, e a inserção do setor na política global de redução de emissões. Foram questionados e são expostos para efeito deste artigo:

- o turismo e o clima apresentam estreita relação, tendo em vista que o turismo pode ser afetado por emissões de gases causadores do efeito estufa e, ao mesmo tempo, contribuir para agravar o problema. É possível identificar oportunidades e desafios para o desenvolvimento sustentável do turismo brasileiro observando os cenários projetados pelas mudanças climáticas?

\section{Análise dos dados}

Para análise do conteúdo, os dados brutos foram tratados de maneira a serem significativos e válidos. Nesse sentido, as categorias de análise: mudanças climáticas, turismo, adaptação, mitigação, política climática e baixo carbono servem para transformar as informações obtidas junto aos especialistas em dados que sejam interpretáveis e tenham significado conforme o objetivo da pesquisa.

O cruzamento dos dados foi organizado em torno da categorização que consistiu em descobrir os núcleos de sentido que compõem o aporte de cada especialista. Em consonância com Bardin (2011), elegeu-se a regra
- poderá o turismo modificar-se e adaptar-se com êxito aos novos cenários socioambientais apontados a partir das mudanças climáticas?

- considerando a relação local-global, intrínseca ao fenômeno das alterações climáticas, é possível articular ações locais com as propostas internacionais a respeito do tema: política climática e turismo? Como?

- como promover um desenvolvimento de baixa emissão de gases de efeito estufa, tendo o turismo como atividade que contribua para essa redução?

- o turismo comunitário pode ser considerado uma atividade de baixo carbono, contribuindo com o enfrentamento da crise ambiental, mais especificamente das mudanças climáticas?

de enumeração com presença (ou ausência), o que na abordagem qualitativa recorre a indicadores não frequências suscetíveis de inferências. Levou-se em consideração a regra de exclusividade, em que uma frase presente em uma categoria não pode estar em outra, bem como a regra de homogeneidade, princípio que define uma categoria como sendo necessária, a fim de que houvesse apenas uma dimensão na análise. Finalmente, com sucessivas leituras, foi possível sistematizar as contribuições dos especialistas e, a partir dessas informações, relativizá-las com o propósito deste artigo, formatando assim os resultados.

\section{RESULTADOS E CONCLUSÕES}

\section{Desafios e oportunidades para o desenvolvimento sustentável do turismo nacional: cenários projetados pelas mudanças climáticas}

Alguns cenários indicam que as mudanças climáticas poderão representar potenciais riscos para o desenvolvimento do turismo mundial. Mudanças nos padrões meteorológicos nos destinos turísticos e nos países emissores podem afetar significativamente o bem-estar dos turistas, as decisões na escolha do destino de suas viagens e, consequentemente, diminuir o fluxo da demanda. Contudo, a falta de observações de longo prazo é um fator limitante para diagnosticar e quantificar o papel dos diferentes agentes do clima no sistema turístico. Da mesma forma, o universo das pesquisas realizadas corresponde a regiões específicas, não disponibilizando informações relevantes quando o foco é a atividade turística nacional.

Isso poderia ser justificado pelo fato de que, apesar do crescente debate do turismo e mudanças climáticas a partir da década de 1990, o campo ainda é relativamente inexplorado, devido, principalmente, ao fraco investimento governamental na investigação das dimensões ambiental e social do turismo. No Brasil, de acordo com Ambrizzi (2014) e Marengo (2014), parece ser pouco expressivo o número de estudos interdisci- 
plinares e profissionais ligados ao tema, mesmo entre aqueles que desempenham papel relevante na área das políticas públicas e instituições governamentais.

Reconhecidas as limitações em torno do conhecimento que trata da relação entre turismo e mudanças climáticas (MORENO, 2010; SIMPSON et al., 2008; SCOTT \& LEMIEUXA, 2009; GRIMM et al., 2013), os resultados aqui apresentados têm por base a revisão bibliográfica e o encontro de saberes identificados entre os especialistas consultados.

No Brasil, a atividade turística representa $4 \%$ do produto interno bruto (PIB) nacional. Números do Ministério do Turismo mostram que $71 \%$ dos turistas internacionais usam o avião como meio de transporte para chegar ao nosso país (MTur, 2015). Esses dados vislumbram o turismo como essencial para a economia e, portanto, sua contribuição para o aquecimento global, observando-se o transporte aéreo como principal modal, exige ações de mitigação, para fazer frente aos impactos derivados da atividade e que contribuem para o aquecimento global.

Em relação ao SISTUR (demanda, oferta, espaço geográfico turístico e agentes), os impactos que podem ser esperados a partir do aumento da temperatura global são: redução nas precipitações e aumento em sua variabilidade interanual, aumento dos eventos climáticos extremos e elevação no nível do mar (MARENGO, 2014; AMBRIZZI, 2014; CORIOLANO, 2014); tais eventos podem afetar diretamente a atividade turística. No Quadro 2 são listados os possíveis impactos e consequências das mudanças climáticas no sistema turístico, em cenários prospectivos no Brasil, elaborado a partir das contribuições feitas pelos especialistas consultados (AMBRIZZI, 2014; CORIOLANO, 2014; MACHETE, 2014; BELÉN, 2014; CAMPOS FILHO, 2014; HENRIQUEZ, 2014).

A respeito dos impactos da mudança climática sobre os entornos turísticos (espaço de litoral, montanha, rural, urbano), estes deverão ser afetados de forma desigual, pois dispõem de diversificada oferta de recursos, produtos e destinos, cada qual com diferente grau de relação com o clima. De acordo com o caráter e a escala de análise com que se opera neste trabalho, os informes publicados por instituições como o IPCC (2014) e a OMT (2008), juntamente com dados de estudos científicos (GÖSSLING et al., 2010; GÖSSLING \&
PEETERS, 2015) e o parecer de especialistas (AMBRIZZI, 2014; BELÉN, 2014; MARENGO, 2014; MACHETE, 2014; CORIOLANO, 2014; CAMPOS FILHO, 2014; HENRIQUEZ, 2014), observa-se que zonas e produtos mais vulneráveis estão relacionados aos entornos litoral e montanha. Essa vulnerabilidade aos impactos da mudança climática não é particular no Brasil; tal cenário pode ser verificado em outros destinos turísticos mundiais (MELLO et al., 2009).

No cenário nacional, Coriolano (2014) ressalta um exemplo emblemático da atividade turística na zona costeira do Ceará, vulnerável aos impactos ambientais. Para a especialista:

\begin{abstract}
As alterações na temperatura do planeta podem causar alterações em fenômenos climáticos, como o El Niño, por exemplo, e gerar aumento do nível do mar. Isso pode aumentar eventos de inundação e agravar processos erosivos (perda de praia). Além disso, a infraestrutura urbana e turística localizada na zona costeira pode ser danificada. A alternativa para reduzir os danos desses impactos pode ser a implantação de obras de engenharia costeira, mas, em contrapartida podem afetar a balneabilidade e a beleza cênica do litoral (CORIOLANO, 2014. Especialista consultada).
\end{abstract}

Temperaturas mais amenas no sul do país podem favorecer o turismo fora do período de verão (AMBRIZZI, 2014). Destinos costeiros poderão ter algumas de suas praias afetadas, principalmente entre os meses de julho a setembro, quando os ventos são mais fortes e as marés estão mais altas. As causas do avanço do mar estão relacionadas a efeitos locais (erosão, atividades humanas, engenharia e ocupações) e globais do aquecimento do planeta. Também existem variações temporais do nível do mar que podem influir nos números de longos períodos. Como consequência, a água invade e destrói a infraestrutura construída na orla marítima (MARENGO, 2014; AMBRIZZI, 2014) Especialistas entrevistados.

Os cenários simulados a partir da mudança climática no turismo litorâneo brasileiro apontam que poderá haver deslocamento da temporada turística devido à intensificação de um período estival mais quente e seco, o que poderá favorecer a ampliação e desestacionalização da mesma. Poderá ainda ocorrer uma fragmentação do período de férias laborais, para melhor aproveitamento de condições atípicas do clima (por excesso de calor fora de temporada) e melhores condições econômicas (promoção de viagens com preços mais acessíveis). 
É possível identificar oportunidades para o setor de turismo decorrentes de mudanças climáticas. Verões cada vez mais quentes poderão promover economias locais de forma indireta com a venda de produtos destinados à proteção contra os raios ultravioletas (protetores solares, chapéus, óculos etc.) e produtos paliativos do calor (bebidas, alimentos apropriados, sorvetes, ar condicionado, ventiladores etc.), que passam a ser necessidade básica tanto de moradores locais quanto de turistas (MARENGO, 2014).

Entretanto, Belén (2014) destaca que tanto os desafios como as oportunidades dependem de variáveis que influenciam o setor de turismo de forma dire-

Quadro 2 - Possíveis impactos e consequências das mudanças climáticas no sistema turístico, cenários prospectivos no Brasil.

\begin{tabular}{|c|c|c|}
\hline Fatores & Impactos & Consequências \\
\hline $\begin{array}{l}\text { Aumento de } \\
\text { temperatura } \\
\text { (oferta e } \\
\text { demanda) }\end{array}$ & $\begin{array}{l}\text { - Redução do período adequado de } \\
\text { exposição solar } \\
\text { - Stress térmico } \\
\text { - Aumento na incidência de câncer de pele }\end{array}$ & $\begin{array}{l}\text { - Redirecionamento da demanda para outros } \\
\text { destinos potenciais (Unidade de Conservação) } \\
\text { - Adaptação do período da viagem } \\
\text { - Fragmentação do período de férias com } \\
\text { diminuição da estadia } \\
\text { - Má qualidade da experiência }\end{array}$ \\
\hline $\begin{array}{l}\text { Eventos } \\
\text { extremos* } \\
\text { (espaço } \\
\text { geográfico } \\
\text { turístico, } \\
\text { demanda, oferta } \\
\text { e agentes) }\end{array}$ & $\begin{array}{l}\text { - Destruição da infraestrutura turística } \\
\text { - Bloqueio de vias de acesso } \\
\text { - Interrupção nos meios de comunicação } \\
\text { - Mudanças do ciclo hidrológico }\end{array}$ & $\begin{array}{l}\text { - Especulação imobiliária } \\
\text { - Contaminações e propagação de doenças } \\
\text { - Falta de água potável } \\
\text { - Alto custo de recuperação } \\
\text { - Baixa capacidade de atendimento } \\
\text { emergencial (resgate, evacuação, serviços } \\
\text { médicos) } \\
\text { - Indisponibilidade de acomodações de } \\
\text { emergência, aconselhamento e atendimento } \\
\text { às vítimas } \\
\text { - Aumento no preço das viagens } \\
\text { - Insegurança } \\
\text { - Má qualidade da experiência } \\
\text { - Desconfiança do consumidor }\end{array}$ \\
\hline $\begin{array}{l}\text { Elevação do nível } \\
\text { do mar } \\
\text { (espaço } \\
\text { geográfico } \\
\text { turístico, oferta e } \\
\text { agentes). }\end{array}$ & $\begin{array}{l}\text { - Degradação da praia } \\
\text { - Branqueamento de corais } \\
\text { - Erosão costeira } \\
\text { - Destruição de manguezais }\end{array}$ & $\begin{array}{l}\text { - Diminuição do espaço junto à areia para o lazer } \\
\text { - Impactos na reserva de água doce } \\
\text { - Alto custo da restauração da orla }\end{array}$ \\
\hline
\end{tabular}

*Tempestades tropicais, furacões, inundações, movimento de massa de solo, secas etc. 
ta, quando se analisam os impactos do clima sobre a atividade. Para a especialista consultada, essas variáveis são: "el ámbito territorial, la escala de análisis, la modalidad turística, el elemento del sistema turístico contemplado (demanda turística / espacio geográfico / oferta turística / agentes y operadores del mercado) y el marco temporal". A especialista aponta ainda que: "cada destino debe realizar estudios detallados de vulnerabilidad y establecer sus prioridades de desarrollo, antes de diseñar estrategias que permitan adaptarse al cambio climático y mitigar sus efectos, maximizando las oportunidades y minimizando los inconvenientes" (BELÉN, 2014. Especialista consultada).

Campos Filho (2014) destaca na análise dos impactos a escala temporal e espacial a ser adotada, e as características do local a ser estudado. Para o especialista, considerando um cenário macro, a mudança climática tem impactado negativamente todos os ambientes rurais e urbanos, incluindo destinos turísticos vulneráveis (atuais e potenciais), independentemente de bioma e/ou outras características geográficas.

Ao questionar os especialistas sobre a relação localglobal como intrínseca ao fenômeno das alterações climáticas, identificou-se que o setor do turismo, ao fazer frente aos novos desafios impostos pela mudança do clima, deve considerar a relação local-global, articulando ações conjuntas a respeito do tema. Contudo, Marengo (2014) adverte que, apesar de a articulação global/local ser possível, é recomendável haver sinergia das ações, uma vez que não adianta reduzir as emissões localmente se o "mundo continua liberando gases na solta". Ainda segundo o especialista, deve haver grande coordenação entre ações locais, no contexto de políticas ambientais, regionais e globais.
Para Ambrizzi (2014), o Brasil, como um todo, deve mostrar ao mundo que está fazendo sua parte na redução de emissões de GEE na adoção de um desenvolvimento econômico sustentável; talvez assim, o país possa influenciar mais decisivamente outras nações e, com isso, consiga propor projetos e temas a outros países rumo a um consenso, inclusive com aqueles que não assinaram o acordo global de redução em Kyoto (Protocolo de Kyoto).

Para que as ações direcionadas ao enfrentamento dos desafios impostos pela mudança do clima alcancem seus propósitos e revertam-nos em benefícios às comunidades receptoras, turistas e empresas de turismo, são necessárias parcerias entre os diversos segmentos, no sentido de legitimar as ações e unir esforços em prol de objetivos comuns. Reconhecendo essa necessidade, Redclift (2014) aposta na ação coletiva, na legitimidade e na força da sociedade civil: "There needs to be specified links between individual and collective action and the need for strong community involvement. The key is the strength and legitimacy of civil society and its institutions" (REDCLIFT, 2014. Especialista consultado).

Oportunidades surgem das mudanças, e o setor de turismo deverá aproveitar o momento para criar condições de desenvolvimento de uma economia de baixo carbono. Coloca-se, assim, a necessidade de os destinos turísticos brasileiros de litoral, mais vulneráveis a eventos extremos (falta de água, ondas de calor, furacões, inundações, deslizamentos, elevação do nível do mar etc.), buscarem adaptar-se aos novos cenários ambientais. Dessa adaptação, podem emergir novas formas de fazer turismo, mais solidário e sustentável, privilegiando uma atividade de menor impacto ambiental.

\section{Implicações da política de baixo carbono para o desenvolvimento do turismo a partir do "olhar" dos especialistas}

O objetivo global da política e estratégias de mitigação das mudanças climáticas é o de contribuir para o desenvolvimento de uma economia de baixo carbono, buscando ecoeficiência nos diversos setores produtivos. A atividade turística também tem buscado mitigar seu tributo, incentivando novas formas de fazer turismo, valorizando a experiência da viagem e contribuindo na geração de benefícios sociais, econômicos e ambientais, por meio da mitigação das emissões de carbono em atividades turísticas (GRIMM, 2016).

O turismo em si contempla amplo panorama no cenário mundial, sobretudo envolvendo planos estratégicos de ampliação das atividades do setor, bem como discursos sobre os cenários atuais e projeções no que diz respeitos à sua participação na mitigação de impactos climáticos em escala global. Diante disso, questionouse qual a forma de promover um desenvolvimento de 
baixa emissão de GEE, tendo o turismo como atividade que contribua para essa redução, e se o turismo comunitário poderia representar uma condição no enfrentamento da crise ambiental, mais especificamente das mudanças climáticas.

Ao se analisar as colocações feitas pelos especialistas, percebe-se que há consenso no fato de que o setor de turismo deve trabalhar no sentido de implantar ações e estratégias de mitigação, reduzindo o consumo de energia, melhorando a eficiência energética, implantando novas tecnologias na aviação e aumentando a utilização de energias renováveis e o sequestro de carbono por meio de sumidouros. Independentemente do sucesso na redução das emissões de GEE, Scott et al. (2016) destacam que haverá, sem dúvida, custos associados à adaptação exigida pela mudança climática.

A capacidade do setor em adaptar-se é considerada relativamente elevada, devido à sua natureza dinâmica e, portanto, haverá oportunidades importantes para a redução de vulnerabilidade das comunidades receptoras às mudanças climáticas por parte do turismo, ao mesmo tempo que contribui nas ações de mitigação (OMT, 2007; OMT, 2008; SIMPSON et al., 2008; MORENO, 2010). Neste sentido Belén (2014), destaca:

\footnotetext{
Quizás, con carácter genérico, el principal reto que el cambio climático plantea al turismo sea el entendimiento entre sector público y privado. En este sentido, el sector público debe ser capaz de proporcionar un conocimiento adecuado de los impactos (positivos y negativos) y de las mejores estrategias de adaptación y mitigación. También el sector público debe ser capaz de crear un marco normativo y de incentivos que estimulen la implicación de la empresa privada. Sólo de este modo, el sector privado será capaz de considerar el cambio climático en la toma de decisiones, tanto a corto como a largo plazo (BELÉN, 2014. Especialista consultada).
}

Para empresas, organizações ou instituições de turismo, neutralidade de carbono significa ter contribuição líquida zero de GEE liberados na atmosfera. Isso inclui todas as atividades diretamente controladas, incluindo viagens, compra de bens e serviços e comportamento diário de funcionários e turistas (MUKOGO, 2014). A neutralidade, ou baixa emissão de carbono, pode ser conseguida através de melhorias na organização, de eficiência das operações e equipamentos e com a oferta de atividades de lazer de menor impacto (AMBRIZZI, 2014).
A mitigação pode ser realizada por meio da inovação tecnológica e de mecanismos de mercado. Contudo, os especialistas apontam que os efeitos mais significativos da redução das emissões só podem ser alcançados com a mudança comportamental do turista, que tem mostrado, em alguns casos, características de pegada de carbono cada vez maior, como é o caso do crescente uso do transporte aéreo que, de acordo com a OMT (2008), representa $42 \%$ dos meios utilizados para deslocamento de turistas. Há também o aumento da atividade turística, com deslocamentos aéreos cada vez mais distantes, em que iniciativas de mitigação têm que mediar objetivos muitas vezes conflitantes: de um lado a necessidade de redução de emissões, do outro a necessidade de aumentar a demanda.

Da mesma forma, governos devem formular políticas públicas prevendo a integração das questões ambientais em todas as políticas de desenvolvimento do turismo. É sugerida a criação de normas de emissão de GEE para funcionamento e licenciamento de novas instalações, padrões de eficiência energética para a hotelaria e transporte, normas de reaproveitamento e uso eficiente da água, exigir de novos projetos de turismo que contenham, entre outras, iniciativas de contribuição para minimizar o impacto ambiental. Incentivos como créditos fiscais são indicados para encorajar empresas a aderir a requisitos de mitigação, e até mesmo propor suas próprias iniciativas (AMBRIZZI, 2014; BELÉN, 2014; MACHETE, 2014. Especialistas consultados).

Campos Filho (2014. Especialista consultado) adverte ainda que:

\footnotetext{
Parte da atividade turística tem adotado estratégias de modificação e adaptação aos cenários socioambientais apontados a partir das mudanças climáticas, como a implantação de critérios de sustentabilidade nas suas diferentes dimensões, com ênfase na ambiental, ancoradas ou não em processos de certificação.

\begin{abstract}
Um bom começo é adotar as medidas recomendadas pelo extinto Conselho Nacional de Turismo Sustentável que em parte foram inclusas nas normas de certificação de meios de hospedagem em vigor, que tem recomendações e exigências do ponto de vista ambiental, social e econômico.
\end{abstract}

Colocadas as possibilidades de o turismo contribuir com ações de mitigação, é importante destacar que iniciativas desenvolvidas - como por exemplo, no setor de transporte aéreo com a regulação/controle do 
tráfego e o aumento do preço do petróleo - buscando reduzir as emissões desse sistema, podem ter um impacto significativo nos custos e na disponibilidade desse modal, afetando negativamente a mobilidade dos turistas e diminuindo a demanda para determinados destinos. Isso poderá induzir mudanças na demanda, substituindo destinos de longa distância por outros mais próximos, regionais e locais, mas, consequentemente, afetar a balança comercial de países que dependem economicamente da atividade na promoção de trabalho e renda (GRIMM, 2016).

Ademais da mitigação, outros desafios são impostos ao turismo quando o tema é o desenvolvimento de uma economia de baixo carbono. A sustentabilidade, por exemplo, que não é prioridade entre algumas empresas do setor, deve ser posicionada como uma oportunidade de mercado e não uma obrigação, uma vez que a demanda cada vez mais consciente de questões sociais e ambientais tem buscado destinos comprometidos com o turismo responsável.

Da mesma forma, a percepção de que o turismo, como emissor de GEE, não está alinhado à sustentabilidade deve ser combatida. A eficiência do setor como uma economia de baixo carbono passa pelo desenvolvimento sustentável e, para isso, esforços devem ser concentrados no sentido de promover medidas que possam ser aplicadas no setor, reduzindo as emissões de GEE. Entre as medidas mais simples e eficazes:

- incentivar a renovação da frota aérea por aeronaves energeticamente mais eficientes; melhorar a gestão do espaço aéreo reduzindo ineficiências nas rotas; promover mudanças no comportamento dos turistas para reduzir o uso do automóvel. Localmente, incentivar o uso de transporte alternativo (ônibus, bicicleta) e promover o turismo regional, que dispensa o transporte de longa distância;

- no alojamento, implantar medidas que visem a reduzir o gasto energético e o consumo de água. Incentivar mudanças no comportamento dos turistas para alcançar economia de consumo;

- na gastronomia, promover a cozinha tradicional do lugar, consumindo produtos locais, diminuindo ou mesmo dispensando o transporte de mercadorias em larga distância;
- promover formas alternativas de turismo, que valorizem uma atividade de menor escala e mais integrada ao entorno ecológico e cultural, associando o turismo a outras atividades produtivas tradicionais.

Sob essa perspectiva, o turismo comunitário, que acontece em menor proporção, vem sendo disseminado em comunidades tradicionais e em regiões onde populações buscam mecanismos de adaptação frente às crises ambiental e climática. Essas comunidades encontram, no turismo, uma estratégia de diversificação econômica e geração de trabalho e renda. De acordo com o especialista consultado, Henriquez (2014): "un turismo de bajo impacto sin dudas puede convertirse en atributos diferenciadores a la hora de programar un viaje con fines de turismo beneficiando con ello a comunidades locales que actúan en modalidades de turismo comunitario, solidario o sustentable".

O turismo comunitário, solidário e sustentável sugere uma atividade de baixo impacto, uma vez que essa modalidade não demanda grandes estruturas para sua viabilização, vem contribuindo para a preservação e para a valorização das culturas tradicionais e não possui sazonalidade de veraneio típica do turismo convencional. A compreensão dos impactos climáticos e as respostas mitigadoras e adaptativas poderiam ser incorporadas à gestão desses destinos e regiões. Porém, Ambrizzi (2014) aponta que isso demandará maior esforço interdisciplinar, inter-relacionando todos os setores econômicos, entre eles o turismo.

Nas experiências e iniciativas do turismo comunitário, além dos benefícios citados, é reconhecida uma nova proposta de relação humana e institucional, que busca superar deficiências da lógica do mercado vigente. No entanto, o especialista consultado (HENRIQUEZ, 2014) adverte que "no todas las prácticas comunitarias son sustentables, hay que tener cuidado en eso. Para esto es necesario trabajar en una planificación a doc con la gente que pretende trabajar en turismo estableciendo parámetros de organización y fiscalización local (autocertificación)".

Entre os especialistas consultados, cuja área de ação está vinculada ao turismo, há consenso ao indicar as possíveis contribuições dessa modalidade, com ações 
que visem à mitigação das mudanças do clima. Entre as recomendações consideradas, destacam-se:

- evitar vinculações com os princípios de reprodução, comercialização e consumo em massa de bens e serviço padronizados, desconectando-se do objetivo de privilegiar a diversidade e a capacidade de inovação que as comunidades tradicionais possuem, a partir de seus modos de vida, cultura e história;

- não fomentar a homogeneização de ideias e desejos dos consumidores - atitude própria do turismo convencional ou de massa -, mas sim a valorização da cultura, interesses, valores e formas de vida próprias das comunidades receptoras;

- possibilitar que o turismo comunitário aconteça em localidades que realmente o desejam, sem destruir sua liberdade de escolha; e

- não promover o desenvolvimento de mais uma modalidade de turismo, privilegiando a ação coletiva em detrimento do fomento à competição, à geração de lucro e à comercialização em larga escala como fim maior.

Além disso, a mudança climática demandará do setor de turismo o desenvolvimento de novas estratégias econômicas, tecnológicas e culturais e, uma vez que a atividade se encontra envolvida com a atenuação da pobreza, seria um erro adotar um enfoque reducionista com relação ao clima que possa perder de vista qualquer oportunidade.

Observa-se que, nos próximos anos, o fenômeno da mudança climática deverá estar presente nas políticas de desenvolvimento e gestão do turismo e, considerando que o turismo é uma atividade que contribui direta e indiretamente para o aquecimento global, este deve também internalizar essa dimensão e considerar estratégias adequadas de mitigação em seu planejamento (MARENGO, 2014; AMBRIZZI, 2014; CAMPOS FILHO, 2014. Especialistas consultados).

Frente ao exposto, pode-se indicar que o turismo, enquanto setor econômico chave para o desenvolvimento de muitas regiões, desempenha papel importante na redução da pobreza de muitas comunidades, colaborando para alcançar os ODS das Nações Unidas. Da mesma forma, é um setor que pode contribuir para a mitigação, reduzindo os efeitos colaterais das mudanças climáticas. Portanto, sugere-se que a educação e a informação do cidadão/turista sobre problemas ambientais e climáticos e sobre a forma como cada um pode colaborar com medidas de mitigação e adaptação são fundamentais para a redução de emissões de GEE pelo setor turístico.

\section{CONSIDERAÇÕES FINAIS}

Ao se analisar as complexas relações entre turismo e mudança climática e, em particular, os efeitos que essas mudanças geram em diferentes destinos turísticos, nota-se que são necessárias medidas no setor, que deve se adaptar às instáveis condições do clima, adotando ações preventivas para enfrentar e minimizar possíveis efeitos das mudanças climáticas.

Nesse momento, é cabível expor suspeitas de que a institucionalização, muitas vezes, não apresenta funcionalidade ou ainda de que seja composta por sistemas regulatórios subutilizados, ignorados ou mesmo que não refletem a realidade local. Qualquer que seja a situação, a atuação isolada por vezes é inócua, tornando inoperantes ações mitigadoras que tenham algum significado plausível. Portanto, são necessárias medidas que visem à adequação de políticas públicas de turismo, subscrevendo acordos intergovernamentais, governamentais e multilaterais afins, na busca de soluções associadas que contribuam para a redução das emissões de GEE pelo setor em escala global, regional e local.

Uma das tendências recentes no setor de turismo parece ser a adoção de medidas que visam a atenuar os impactos ambientais de suas atividades, como hotelaria e recreação, e que permitam reduzir o consumo de recursos hídricos e energéticos, melhorar os procedimentos inerentes ao tratamento de resíduos, entre outros. Essa mudança de comportamento é motivada tanto pelas regulações legais como pela redução de custos operativos e pelo aperfeiçoamento da imagem pública da empresa, que influencia a competitividade junto aos clientes. Esse gênero de medidas pode ser aplicado às várias regiões do globo e aos tipos de atividades desenvolvidas; contudo, cada região poderá sentir vulnerabilidades específicas às caracteristicas do território, havendo necessidade de iniciativas de mitigação e adaptação específicas para cada lugar. 
Na verdade, não existe um conjunto de medidas de mitigação e adaptação únicas. Todo o sistema turístico pode e deve tomar medidas para reduzir as emissões de gases associados a suas atividades: para os turistas, a escolha de meios de transporte menos contaminantes, a procura de produtos e atividades de pegada de carbono zero e a compensação de suas emissões quando fizer uso do transporte aéreo; para os agentes, a promoção de produtos com períodos de estadia mais longos e destinos mais próximos e o desenvolvimento de produtos e atividades de pegada de carbono zero. Governos e comunidades devem buscar desenvolver um marco normativo que estimule a economia energética e programas de educação e conscientização social. No transporte e alojamento, a eficiência energética e hídrica tem sido a alternativa mais indicada.
Do mesmo modo, observando o caminho inverso dessa abordagem, é questionável a validade de julgamentos sob a responsabilidade turística como deflagradora de mudanças climáticas. Talvez, mais modestamente, essas alterações em escala local ou regional apresentem impactos ambientais severos e localizados, que podem ser detectados nas pesquisas in loco, para posterior projeções ou consolidação de dados numa tentativa de projeção global. Apesar de os modelos do IPCC serem desenvolvidos em alta resolução, ainda carecem de conhecimento microclimático, podendo gerar previsões pouco precisas. Todavia, esses aspectos devem ser minimizados com o passar do tempo e não devem ser considerados como percalços às imprescindíveis ações de mitigação e adaptação a este fenômeno que é, provavelmente, um dos maiores desafios desse século.

\section{REFERÊNCIAS}

AMBRIZZI, T. Mudanças climáticas no cenário nacional: impactos, possibilidades e desafios para o turismo. Especialista consultado. set. 2014.

BARDIN, L. Análise de conteúdo. São Paulo: Edições 70, 2011.

BELÉN, M. M. G. Turismo, clima e mudanças climáticas: uma estreita relação. Especialista consultada. mar. 2014.

BENI, M. C. Política e Planejamento do turismo no Brasil. São Paulo: Aleph, 2006.

CAMPOS FILHO, A. V. Turismo de Base Comunitária e as mudanças climáticas. Especialista consultado. jun. 2014.

CANDIOTTO, L. Z. P. Considerações sobre o conceito de turismo sustentável. Formação, v. 1, n. 16, p. 48-59, 2011.

CORIOLANO, L. N. Turismo de Base Comunitária e as mudanças climáticas. Especialista consultada. jan. 2014.

Declaração de Berlim: transformar o turismo. 2017. Disponível em: https://issuu.com/raizesds/docs/declara ${ }^{\circ}$ de_berlim_transformar_.Acesso em: mai. 2017.

FAYOS-SOLÀ, E. Cambio climático y turismo: realidad y ficción. Madri: Universidad de Valência, 2010. p. 287-313.

FITCHETT, J. M.; GRANT, B.; HOOGENDOORN, G. Climate change threats to two low-lying South African coastal towns: risks versus perceptions. South African Journal of Science, v. 112, n. 5/6, maio/jun. 2016.

FOLADORI, G. Limites do desenvolvimento sustentável. São Paulo: Editora da Unicamp/Imprensa Oficial, 2001.

GIMÉNEZ, J. F. V. Debate: turismo y cambio climático. In: FERNANDEZ, J. I. P. Turismo y cambio climático. Revista de Análisis Turístico, España, n. 4, p. 100-112, 2. ${ }^{\circ}$ sem. 2007.

GÖSSLING, S.; HALL, M.; PEETERS, P.; SCOTT, D. The Future of Tourism: Can Tourism Growth and Climate Policy be Reconciled? A Mitigation Perspective. Tourism Recreation Research, n. 2, v. 35, p. 119-130, 2010. 
GÖSSLING, S.; HALL, M.; SCOTT, D. The challenges of tourism as a development strategy in an era of global climate change. In: PALOSOU, E. (ed.). Rethinking development in a carbon constrained world. Development cooperation and climate change. Helsinki: Ministry of Foreign Affairs, p. 100-119, 2009.

GÖSSLING, S.; PEETERS, P. Assessing tourism's global environmental impact 1900-2050. Journal of Sustainable Tourism, v. 23, n. 5, p. 639-659, 2015.

GRIMM, I. J. Mudanças climáticas e turismo: estratégias de adaptação e mitigação. 247 p. Tese (Doutorado) - Programa de Pós-graduação em Meio Ambiente e Desenvolvimento, Universidade Federal do Paraná, Curitiba, 2016.

GRIMM, I. J.; PRADO, L.; GIACOMITTI, R. B.; MENDONÇA, F. A. Mudanças climáticas e o Turismo: desafios e possibilidades. Revista Brasileira de Climatologia, ano 8, v. 11, jul./dez. 2013.

HALL, C. M.; AMELUNG, B.; COHEN, S.; EIJGELAAR, E.; GÖSSLING, S.; HIGHAM, J.; LEEMANS, R.; PEETERS, P.; RAM, Y; SCOTT, D. On climate change skepticism and denial in tourism. Journal of Sustainable Tourism, n. 1, v. 23, p. 4-25, 2015.

HENRIQUEZ, C. Turismo de Base Comunitária e as mudanças climáticas. Especialista consultado. jun. 2014.

INTERGOVERNAMENTAL PANEL ON CLIMATE CHANGE - IPCC. Summary Policymakers. 2014. Disponível em: <http:// www.climatechange2013.org/>. Acesso em: 24 jun. 2014.

LEFF, H. Discursos sustentáveis. São Paulo: Cortez, 2010. p. 133-157.

LINO, G. L. A fraude do aquecimento global: como um fenômeno natural foi convertido numa falsa emergência mundial. 3. ed. Rio de Janeiro: Capax Dei, 2009.

MACHETE, R. Clima e turismo num contexto de mudanças climáticas. Finistera, XLVI, v. 91, p. 139-154, 2011.

MACHETE, R. Turismo, clima e mudanças climáticas: uma estreita relação. Especialista consultada. mar./abr. 2014.

MARENGO, J. Mudanças climáticas no cenário nacional: impactos, possibilidades e desafios para o turismo. Especialista consultado. set./out. 2014.

MARTINS COSTA, T. V. de A. Mudanças climáticas: uma questão geopolítica. In: ENCONTRO NACIONAL DA ECOECO, 9., Brasília, 2011. Anais..., 2011. Disponível em: <http://www.ecoeco.org.br/conteudo/publicacoes/encontros/ix_en/ GT3-108-101-20110615165555.pdf>. Acesso em: 23 out. 2014.

MATZARAKIS, A. Assessment method for climate and tourism based on daily data. In: MATZARAKIS, A.; DE FREITAS, C. R.; SCOTT, D. (Orgs.). Developments in Tourism Climatology. Freiburg: Commission Climate, Tourism and Recreation/ International Society of Biometeorology, 2008. v. 8. p. 52-58.

MELLO, C.; MCKEOWN, J.; MINNINGER, S. (Orgs.). Disaster Prevention in Tourism Perspectives on Climate Justice. Germany: Ecumenical Coalition on Tourism in cooperation with EED Tourism Watch, 2009.

MINISTÉRIO DO TURSIMO - MTur. Mais de 6,4 milhões de turistas estrangeiros visitaram o Brasil em 2014. 2015. Disponível em: <http://www.turismo.gov.br/ultimas-noticias/5227-mais-de-6,4-milh\%C3\%B5es-de-turistas-estrangeiros-visitaram-o-brasilem-2014.html>. Acesso em: abr. 2015.

MOLION, L. C. B. Aquecimento global: uma visão crítica. Revista Brasileira de Climatologia, v. 3/4, p. 7-24, 2008.

MORENO, A. Climate Change and Tourism Impacts and Vulnerability in Coastal Europe. Tese (Doutorado) - Maastricht University, Universitaire PERS, Maastricht, 2010. Disponível em: <http://arno.unimaas.nl/show.cgi?fid=20143>. Acesso em: 17 jul. 2014. 
MUKOGO, R. Greening of the Tourism Sector an Effective Mitigation Measure against Climate Change. Vermont: International Institute for Peace through Tourism, 2014. Disponível em: <http://www.iipt.org/IIPT\%20Book/articles/ Rose\%20Mukogo.Greening\%20of\%20the\%20Tourism\%20Sector\%20an\%20effective\%20Mitigation\%20Measure\%20 against\%20Climate\%20Change.pdf>. Acesso em: 27 maio 2015.

ORGANIZAÇÃO MUNDIAL DO TURISMO - OMT. De Davos a Bali: la contribución del turismo al reto del cambio climático. 2008. Disponível em: <http://www.unwto.org>. Acesso em: maio 2014.

. Turismo internacional: uma perspectiva global. 2. ed. São Paulo: Bookman, 2003b.

. Turismo y cambio climático: Hacer frente a los retos comunes. Consideraciones preliminares de la OMT. 2007. Disponível em: <http://sdt.unwto.org/sites/all/files/docpdf/docuconfrontings.pdf>. Acesso em: 3 maio 2015.

PEETERS, P.; GÖSSLING, S.; BECKEN, S. Innovation Towards Tourism Sustainability: Climate Change and Aviation. International Journal of Innovation and Sustainable Development, v. 1, n.3, p. 184-200, 2006.

REDCLIFT, M.R. Desenvolvimento, mudanças climáticas e turismo. Especialista consultado. set. 2014.

RIBOT, J. Vulnerability before adaptation: toward transformative climate action. Global Environmental Change, v. 21, p. 1160-1162, 2011.

RUSCHMANN, D. Turismo e planejamento sustentável: a proteção do meio ambiente. São Paulo: Papirus, 2008.

SAMPAIO, C. A. C. Perspectiva do turismo comunitário, solidário e sustentável. In: SAMPAIO, C. A. C.; HENRIQUEZ, C.; MANSUR, C. (Orgs.). Turismo comunitário, solidário e sustentável: da crítica às ideias e das ideias à prática. Blumenau: Edifurb, 2011. p. 23-30.

SCOTT, D.; GOSSLING, S.; HALL, M. International tourism and climate change. Wiley Interdisciplinary Reviews: Climate Change, v. 3, p. 213-232, maio/jun. 2012.

SCOTT, D.; GÖSSLING, S.; HALL, C. M.; PEETERS, P. Can tourism be part of the decarbonized global economy? The costs and risks of alternate carbon reduction policy pathways. Journal of Sustainable Tourism, v. 24, n. 1, p. 52-72, 2016.

SCOTT, D.; LEMIEUXA, C. Weather and Climate Information for Tourism. Elsevier, v. 1, 2009.

SCOTT, D.; PEETERS, P.; GÖSSLING, S. Can tourism deliver its "aspirational" greenhouse gas emission reduction targets? Journal of Sustainable Tourism, v. 18, n. 3, p. 393-408, 2010.

SIMPSON, M. C.; GOSSLING, S.; SCOTT, D.; HALL, C. M.; GLADIN, E. Climate Change Adaptation and Mitigation in the Tourism Sector: Frameworks, Tools and Practices. Paris: UNEP, University of Oxford, UNWTO, WMO, 2008. 158 p. 